\title{
Uncertainty in fertility intentions in Britain, 1979-2007
}

\author{
Máire Ní Bhrolcháin and Éva Beaujouan*
}

\begin{abstract}
The paper uses a time series of repeated rounds of the General Household Survey in Great Britain to study uncertainty in fertility intentions. We show that a substantial minority of women are uncertain in their expectations about future childbearing. A comparison of reported uncertainty in GHS rounds 1979-1990 with 1991-2007 reveals that the estimated level of uncertainty is influenced by question format. At the individual level, uncertainty varies largely with demographic status and life stage-age, partnership status, parity and time since previous birth. Evidence from qualitative and quantitative studies, particularly in relation to pregnancy intentions, reinforces the reality of uncertainty about reproductive prospects. We suggest that the measurement of fertility intentions needs improvement. A new theoretical approach to fertility intentions is outlined in brief.
\end{abstract}

\section{Introduction}

Questions on reproductive orientation have a long history in demography. In the UK, they featured in the Royal Commission on Population's study of family limitation (Lewis-Faning 1949). In the US, questions on ideal family size have been asked in Gallup and other commercial surveys since the 1930s, and in demographic surveys since the first Growth of American Families (GAF-I) study (Blake 1966). Birth expectations in the early American fertility surveys, particularly GAF-I and GAF-II, were seen originally as an aid to formulating assumptions about the future fertility of younger women for population projection (Freedman et al. 1959; Whelpton et al. 1966; Kiser 1967). In subsequent years, fertility intentions stimulated further demographic interest, particularly in

\footnotetext{
* Máire Ní Bhrolcháin (correspondence author), Centre for Population Change, School of Social Sciences, University of Southampton, SO17 1BJ Great Britain. Email: mnb2@soton.ac.uk Éva Beaujouan, Centre for Population Change, University of Southampton, Great Britain.
} 
evaluating levels and trends in unwanted fertility worldwide, the interpretation of aggregate fertility trends and the process of reproductive decision-making.

The results of the early investigations bore out initial scepticism (e.g. Westoff et al. 1957; Hauser 1967) about both the stability and predictive power of stated birth expectations. Two decades of research findings to the 1970s were succinctly summarised by Westoff and Ryder (1977) and analysed further by Lee (1980, 1981). While greater consistency was found between expected and actual fertility at the aggregate than at the individual level, this was nevertheless insufficiently close for projection purposes, as expectations were found to reflect current rather than prospective fertility conditions. At the individual level, fertility intentions were, on the one hand, stronger predictors of subsequent fertility than social and economic characteristics but, on the other, their predictive power in an absolute sense was not strong, since substantial inconsistency was found between fertility intentions and outcomes. Besides, intentions/expectations were not stable, either at the aggregate or individual levels. These findings remain valid up to the present, being consistent across diverse studies in a range of developed countries and time periods (Bumpass and Westoff 1969; Cartwright 1976; Cartwright and Wilkins 1976; Woolf and Pegden 1976; Westoff and Ryder 1977; Freedman et al. 1980; Westoff 1981; Noack and Ostby 1985; Rindfuss et al. 1988; Monnier 1989; Morgan and Chen 1992; Van Hoorn and Keilman 1997; Schoen et al. 1999; Morgan 2001; Quesnel-Vallée and Morgan 2003; Berrington 2004; Hagewen and Morgan 2005; Toulemon and Testa 2005; Testa and Toulemon 2006; Hayford and Morgan 2008; Liefbroer 2009; Philipov 2009; Spéder and Kapitány 2009; Morgan and Rackin 2010).

To illustrate with some recent figures, Morgan and Rackin (2010) found, in the US National Longitudinal Survey of Youth, that by age 43 women had on average 0.24 children fewer than they had intended at 18 , and men an average of 0.46 children fewer (net errors). These figures, however, understate the degree to which eventual family size corresponded to early expectations, since undershooting is to some extent offset by over-shooting. Looking at the errors of individuals rather than of the group as a whole, the average woman had 0.87 children more or fewer than she had expected around the age of 24 , and the average man 1.1 children more or fewer than expected (gross errors). Just $43 \%$ of women realised the parity they had intended at age $24,35 \%$ underachieved and $22 \%$ overachieved; the corresponding figures for men are $34 \%, 43 \%$ and $23 \%$.

The past couple of decades has seen an increased focus on reproductive attitudes, particularly in Europe, since while current fertility is mainly below replacement, aggregate measures of ideal/desired family size are nevertheless above current performance (Bongaarts 2002; Goldstein et al. 2003; Testa 2007). Views differ on the significance of this discrepancy. Hagewen and Morgan (2005: 507-8) identify three approaches taken in the literature to interpreting the disparity. It has been seen variously as indicating that period fertility levels are likely to rise to the level of stated preferences, or that declared intentions lag 
behind behaviour and will eventually decline to reach current levels, or that the gap between stated ideals/desires and actual fertility performance need never be closed.

This diversity of views reflects in some measure the incompleteness of our understanding of reproductive orientation, with no definitive clarification of what precisely is represented by answers to questions on ideal, desired and intended family size. It was recognised from the earliest fertility surveys that women or couples could be uncertain about their fertility preferences or intentions. For example, the 1955 GAF-I study featured questions with pre-coded uncertain categories, ${ }^{1}$ and inquired further into how sure respondents were about having their expected family size and also into the reasons for their feeling uncertain. But uncertainty was not reported explicitly in the early American fertility surveys, where it was present only implicitly in tabulations of maximum, minimum and most likely expected births, derived from answers expressed in terms of ranges (Freedman et al. 1959: Chapter 7; Whelpton et al. 1966: Chapter 2). It was Morgan's $(1981,1982)$ classic studies that first addressed the uncertainty in intentions as being of interest in its own right. He points out in particular that uncertainty is inherent to the family formation process and that understanding its role is essential to a full appreciation of reproductive decisions and to the interpretation of aggregate trends in fertility. While the need to recognise uncertainty in the measurement of intentions has been widely accepted since these papers (Morgan 1981, 1982), his deeper message - that deciphering the role of uncertainty is essential to understanding fertility dynamics at both individual and aggregate levels - has received less attention.

In the present paper we take Morgan's perspective forward by examining several further aspects of uncertain fertility intentions. We look first at the prevalence of uncertainty and how this varies with the definition used, and with question format. We then examine the factors associated with uncertainty at the individual level. Drawing on both qualitative and quantitative evidence from a range of studies, we suggest that the uncertainty observed is real, but that more sophisticated concepts and measures are needed in this area. The paper concludes by discussing the demographic significance of the high prevalence of uncertain reproductive attitudes and suggests a new approach to fertility intentions and preferences.

\section{Data}

The data used are from a combined file of the General Household Survey (GHS) for the period 1979-2007. The GHS is an annual continuous survey of the private

\footnotetext{
The GAF-I question on whether a woman/couple expected to have a/another child was precoded "definitely yes", "probably yes", "uncertain”, "probably not”, “definitely no".
} 
household population in Great Britain, carried out by the Office for National Statistics. From 1971 to 1987 and from 2005 to 2007, survey fieldwork was on a calendar year basis and from 1988 to 2004 on a financial year basis. A longitudinal structure was introduced in 2005, as a result of which three quarters of households and persons in the sample in 2006 and 2007 were re-interviews. These repeat interviews are omitted from the present study, and the years 2005-7 combined in analyses by survey year.

\subsection{Weights}

From the GHS 1996 round onwards, weights computed by ONS are available but none have been calculated for prior rounds. We have, accordingly, computed new weights on a consistent basis for the entire series of GHS rounds of 1979 to 2007, designed to adjust for non-response and to calibrate to population distributions by age, sex and region. The methods used are detailed in Beaujouan et al. (2011) and can be briefly described as follows. A set of household weights, applicable to all individuals in each household was generated, first by applying ONS household nonresponse factors and then using Calmar to calibrate to population totals by age and sex, and by a regional classification similar to that of ONS (Sautory 1993; Barton 2001; Ali et al. 2008: Appendix D). A second set of weights applicable to respondents to the Family Information section of the questionnaire was then generated, using the first set of weights, adjusting additionally for individual nonresponse to the Family Information section, and finally calibrating to population totals. These revised, individual-level weights are used in all analyses in the present paper.

\subsection{Questions on fertility intentions}

Fertility intentions questions were asked in the GHS of all women aged 18-44 and ever-married women aged 16-17 from 1979-1985, and of all women aged 16-49 from 1986 to the present. Two measures of intentions are used in the present paper: whether a (further) birth is expected and, among those expecting a (further) birth, the expected age at next birth. Expected parity is also asked in the GHS but is not considered here. 
Table 1:

Birth expectations questions in the General Household Survey 1979-2007.

\begin{tabular}{|c|c|c|}
\hline Question & GHS rounds & Precodes \\
\hline $\begin{array}{l}\text { A. "Do you think that you will have any } \\
\text { (more) children (after the one you are } \\
\text { expecting)?" } \\
\text { (see note } 1 \text { ) }\end{array}$ & $1979-1990$ & $\begin{array}{l}\text { Yes } \\
\text { No } \\
\text { Don't know }\end{array}$ \\
\hline $\begin{array}{l}\text { As above, followed by: } \\
\text { "Could you choose your answers from } \\
\text { this card." }\end{array}$ & $1991-2007$ & $\begin{array}{l}\text { Showcard: } \\
\text { Yes } \\
\text { Probably yes } \\
\text { Probably not } \\
\text { No } \\
\text { Don't know coded by interviewer } \\
1991-93,2000-07\end{array}$ \\
\hline $\begin{array}{l}\text { B. To those answering "don't know" to } \\
\text { question A (in years both with and } \\
\text { without a “don't know" precode): } \\
\text { On the whole do you think... }\end{array}$ & 1991-2007 & $\begin{array}{l}\text {-You will probably have } \\
\text { any/more children? } \\
\text {-Or you will probably not have } \\
\text { any/more children? } \\
\text {-Don't know (1991-1993) }\end{array}$ \\
\hline $\begin{array}{l}\text { C. To those answering “yes" or } \\
\text { "probably yes" to questions A or B (see } \\
\text { note 2) } \\
\text { "How old do you think you will be } \\
\text { when you have your first/next baby } \\
\text { (after the one you are expecting)?" }\end{array}$ & $1979-2007$ & None \\
\hline
\end{tabular}

Notes: 1. The wording of this question varied in minor ways during the period 1979-2007; for example, the words "at all" appeared after "children" in some years. The version given here is that used in the most recent surveys.

2. A question on the number of births expected in total is asked between questions $\mathrm{B}$ and $\mathrm{C}$ here, but it is not used in the present article.

The birth expectations questions used in the present article are set out in Table 1. The wording of the first question remained the same from 1979-2007 (with a minor change in 1995 and 1996; see Smallwood and Jefferies 2003) but the coding changed in 1991. From 1979-1990, explicit uncertainty precodes were not provided. From 1991-2007, a showcard was introduced and "probably yes" and "probably not" were added as precodes, and in some years "don't know" also; "don't knows" were probed further and reclassified as "probably yes" or "probably not" where possible, and coded "don't know" otherwise. Women answering "yes" or "probably yes" to the initial question were asked to state the age at which they expected to have that birth. The difference between the age given and the respondent's age at interview (in completed years) is the measure used in the present article of the expected time to (next) birth. While we briefly cite some data from 1979-1990, below, our principal analysis is based on the GHS rounds 1991-2007, because explicit codes for uncertainty are available during this 
period. Among eligible women in responding households over the period 19912007, 2.8\% refused to answer the Family Information section in which the fertility intentions questions are administered, and a further $4.7 \%$ were proxy respondents who did not complete the Family Information section.

\subsection{Parity}

In recent years, and particularly since 2000, the GHS fertility histories have been affected by over-reporting of childlessness among older women (Murphy 2009). This is, however, due partly to declarations of childlessness by a sizeable minority of women who had children of their own living in the household. The erroneous reporting in the fertility histories, which are collected towards the end of the interview, is probably due to changes in survey procedures, including questionnaire routing, interviewer instructions and the use of computer-assisted self-interview. These changes appear to have reduced the barriers to misreporting arising both from respondent fatigue and a learning effect in a lengthy interview. We have identified these undeclared children from the 1994 round onwards, when a full household relationship matrix was available by which mother-child links could be identified unambiguously and an own-child reconstruction carried out. We then matched own children to the birth history, and those missing from and consistent with a woman's reported history were added to it. The resulting revised fertility histories are used in the present article to define parity at survey. While the revision does not eliminate all errors, those that remain are largely in the histories of women over 45, who are not the subject of the present analysis (for further details, see Ní Bhrolcháin et al. 2011).

\section{How prevalent are uncertain fertility intentions?}

In this section, we examine the prevalence of uncertainty estimated from the General Household Survey 1979-2005/7, and how it varies with alternative definitions. We also provide evidence that the form of the birth intentions question has a substantial influence on the reported level of uncertainty.

\subsection{Definition 1}

Restricting analysis to the period 1991-2007, we first define uncertainty as answering the initial birth expectations question with "probably yes", "probably not", "don't know" or not answering (only 4\% of these were "don't know" or no answer). On this criterion, $31.0 \%$ overall of women under 45 are uncertain during the period 1991-2007, 41.5\% of childless women and $23.7 \%$ of mothers (Table 2). Four in ten women under 35 are uncertain on this first definition, and the figure varies little in that age range, but is over twice the proportion at ages 35-44. Thus, a substantial minority are uncertain about their future childbearing, with 
greater uncertainty among the childless than among women who are already mothers. Uncertainty is more prevalent among younger than among older women, though this is not entirely true of childless women - among women without children in their $30 \mathrm{~s}$ the level of uncertainty reaches around $50 \%$, well above that among younger childless women (see also Berrington 2004; Sobotka 2009; and Ní Bhrolcháin et al. 2010). Figure 1 shows time trends from 1991 to 2005/7 in the prevalence of uncertainty by age, separately for childless and parous women. Little change is evident in the level of uncertainty between 1991 and 2005/7, specific by age and parenthood status. We also see that the differentials by age noted earlier have been present throughout the period.

Table 2:

Per cent whose fertility intentions are uncertain according to three definitions, by age range. Childless, parous and all women aged $<45$. Great Britain, GHS 19912005/7

\begin{tabular}{|c|c|c|c|c|c|}
\hline Sample & Age & Definition 1 & Definition 2 & Definition 3 & $\mathbf{N}$ \\
\hline & & $\begin{array}{c}\text { Probably } \\
\text { yes/not or } \\
\text { don't know }\end{array}$ & $\begin{array}{c}\text { Definition } 1 \text { or } \\
\text { expect birth } \\
5+\text { years } \\
\text { ahead } \\
\end{array}$ & $\begin{array}{c}\text { Definition } 1 \text { or } \\
\text { expect birth } \\
3+\text { years } \\
\text { ahead }\end{array}$ & (unweighted) \\
\hline & & $\%$ & $\%$ & $\%$ & \\
\hline \multirow[t]{7}{*}{ All women } & $18-19$ & 40.8 & 83.7 & 89.9 & 2.732 \\
\hline & $20-24$ & 39.3 & 66.8 & 81.1 & 7.837 \\
\hline & $25-29$ & 39.1 & 47.3 & 60.7 & 9.733 \\
\hline & $30-34$ & 38.6 & 40.7 & 44.7 & 11.442 \\
\hline & $35-39$ & 25.1 & 25.6 & 26.1 & 11.187 \\
\hline & $40-44$ & 10.6 & 10.8 & 10.8 & 10.505 \\
\hline & All ages & 31.0 & 40.4 & 46.6 & 53.436 \\
\hline \multirow[t]{7}{*}{ Childless } & $18-19$ & 41.2 & 85.9 & 92.0 & 2.443 \\
\hline & $20-24$ & 39.2 & 72.8 & 87.9 & 5.625 \\
\hline & $25-29$ & 40.8 & 53.2 & 73.2 & 4.720 \\
\hline & $30-34$ & 50.5 & 54.9 & 63.6 & 3.204 \\
\hline & $35-39$ & 49.2 & 50.6 & 51.9 & 1.980 \\
\hline & $40-44$ & 24.3 & 24.5 & 24.5 & 1.486 \\
\hline & All ages & 41.5 & 62.1 & 73.9 & 19.458 \\
\hline \multirow[t]{7}{*}{ Parity 1+ } & $18-19$ & 35.9 & 57.9 & 66.7 & 289 \\
\hline & $20-24$ & 39.7 & 47.3 & 58.8 & 2.212 \\
\hline & $25-29$ & 37.3 & 40.5 & 46.6 & 5.013 \\
\hline & $30-34$ & 33.1 & 34.2 & 36.1 & 8.238 \\
\hline & $35-39$ & 19.4 & 19.8 & 20.0 & 9.207 \\
\hline & $40-44$ & 8.4 & 8.6 & 8.6 & 9.019 \\
\hline & All ages & 23.7 & 25.3 & 27.5 & 33.978 \\
\hline
\end{tabular}


A prevalence of $40 \%+$ among childless women aged under 45 and $30-40 \%$ of mothers aged under 35 represents a substantial level of uncertainty. It is particularly striking that a sizeable minority are unsure about their fertility expectations up to their late $30 \mathrm{~s}$, when we might expect women to be fairly well informed both about their own preferences and about likely constraints (see also Ní Bhrolcháin et al. 2010). The measure of intentions used thus far is, however, fairly arbitrary. Although questions of this kind have been used in demographic surveys for decades to represent fertility intentions, they are, by and large, of unknown validity, apart from evidence on later outcomes. We explore here two further definitions of uncertainty and return to more general issues of validation in later discussion.

Figure 1a and 1b:

Per cent with uncertain fertility intentions by age and time period. Childless and parous women aged $<45$, weighted. Great Britain, GHS 1991-2005/7
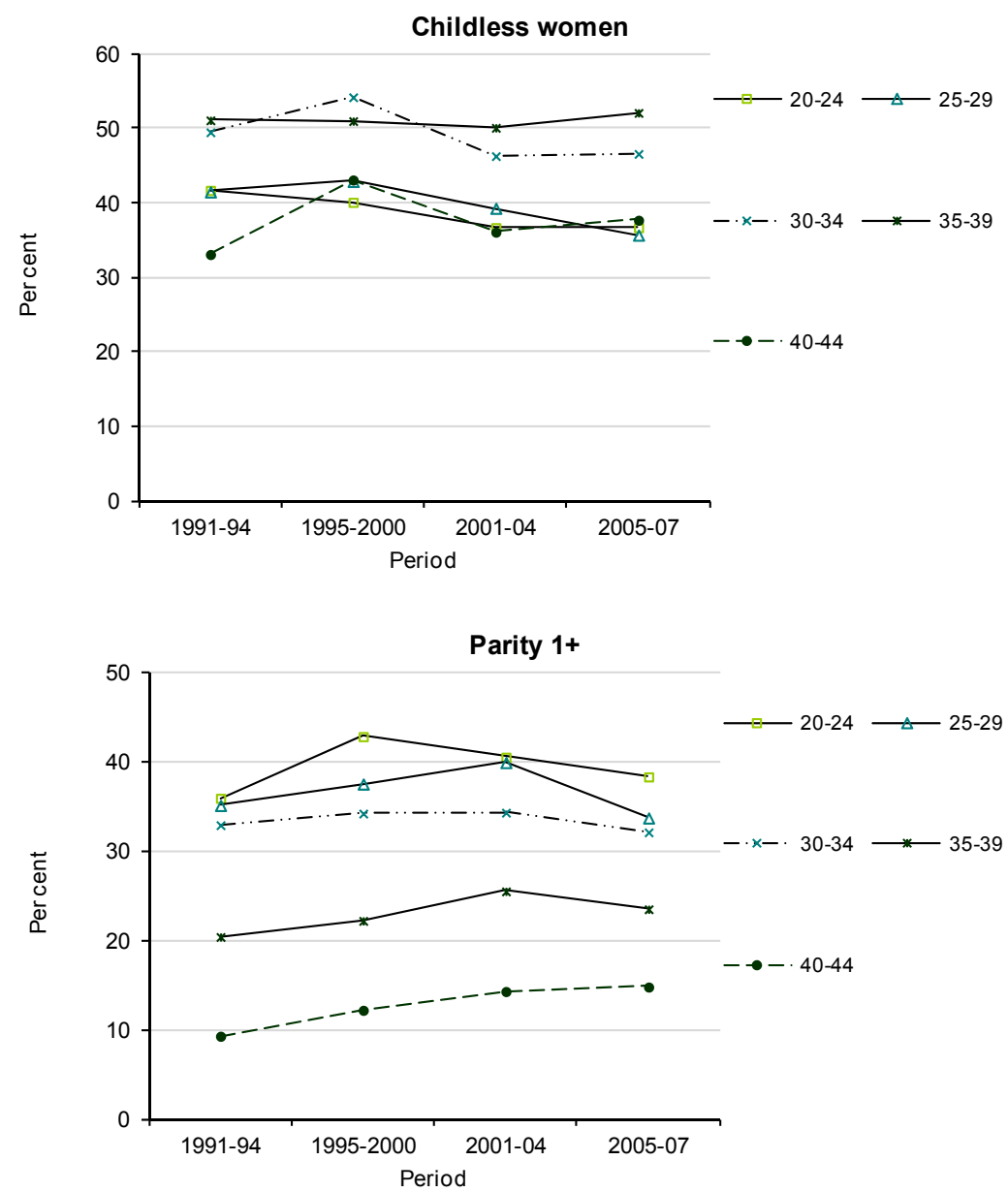


\subsection{Definitions 2 and 3}

We extend the definition of uncertainty by including, along with those classified uncertain under Definition 1, women who answered "yes" to the birth expectation questions and say they expect to have a (further) birth in 5 or more years' time (Definition 2) or in 3 or more years' time (Definition 3). The 3-year time horizon is used in several fertility surveys such as e.g. the UN ECE Gender and Generations Programme. The effect of these extended definitions is thus to reallocate some women from the "yes" to the "probably yes" group. Though these criteria are arbitrary, they are chosen as signifying expectations that are well beyond the immediate future. Evidence supporting the classification of an expected wait of 3 or more years as signifying uncertainty is the substantial heaping (on ages ending in $0,2,5$ and 8) in the distribution of expected age at next birth among women who specify a $3+$ year wait. $^{2}$ In addition, there is an association between the declared level of certainty and the expected time to next birth: $36.4 \%$ of women saying "yes" to the birth expectations question anticipated having a birth within 3 years, compared with $26.6 \%$ of those answering "probably yes".

Prevalence of uncertainty according to the second and third definitions is also given in Table 2, by age and motherhood status. We see that at ages under 35, both revisions have a sizeable impact on the estimated level of uncertainty. In each case, the younger the age, the larger the effect. For example, the proportion of $18-19$ year-olds who are uncertain more than doubles to $83.7 \%$ when adding those who expect a (further) birth in 5+ years' time, and rises further to $89.9 \%$ when adding those expecting a birth 3+ years ahead. The figures for the 20-24 year age group are not far behind. Definitional change affects the estimated level of uncertainty much more among the childless than among mothers, as we might expect from the rarity of long birth intervals. As a result, it widens the gap between childless and parous women. On the $3+$ years criterion, $83.4 \%$ overall of women under 25 , and $62.5 \%$ of under $35 \mathrm{~s}$ - a substantial majority - are unsure of their future childbearing. It is particularly noteworthy that on adding the $3+$ years criterion, nearly all childless women under $25-89.1 \%$ - are uncertain. This is, of course, precisely the age group that is critical in evaluating the stability and predictive validity of reproductive intentions. The level and age profile of the figures suggests that uncertainty pervades women's outlook on childbearing from the earliest stages of the life course right through to the later phases of the reproductive career.

2 Interviewers were instructed to code a response of "mid twenties" as 25 , "late twenties" as 28, "early thirties" as 32 , etc., and so it is not clear how far the heaping is due to actual digit preference on the part of respondents or to interviewer instructions. Regardless of their relative roles, the approximate nature of these responses nevertheless conveys uncertainty on the part of the respondent. 
Figure 2:

Responses to fertility intentions question 1979-2005/7. Women aged $<45$, weighted. Great Britain, GHS 1979-2005/7

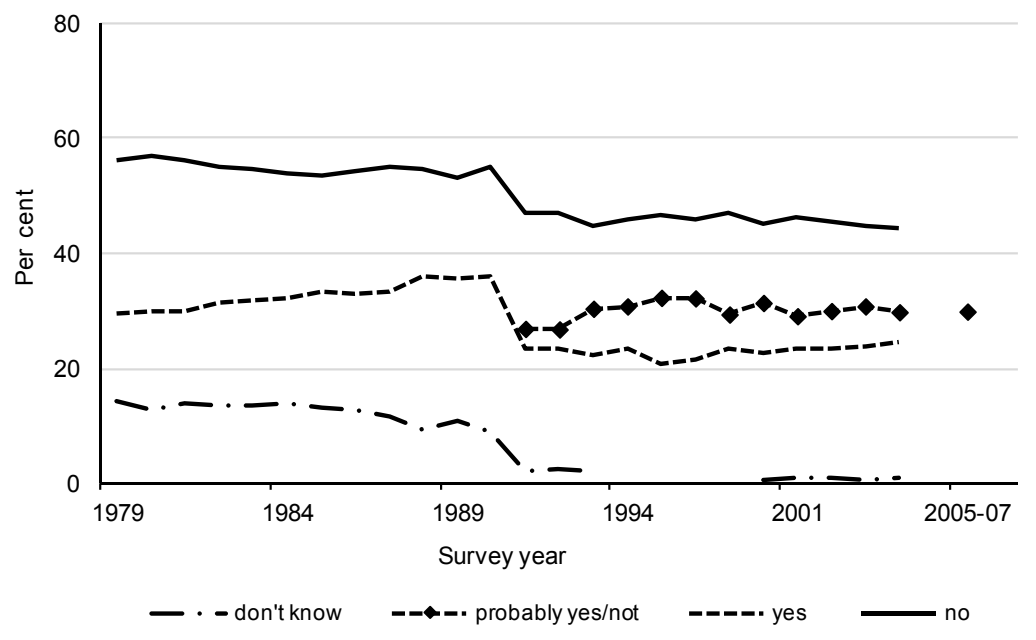

\subsection{Question format}

A further feature of the GHS data allows us to examine the impact of question format on the estimated prevalence of uncertainty. In the preceding sections, we presented GHS results from 1991 to 2005/7 only, because of a change in question format in 1991. That change reveals very clearly the sensitivity of answers to intentions questions to question format. As we saw above in Table 1, the uncertainty precodes, "probably yes/not", for question A on whether women expected a (further) birth at any time in the future were not available before 1991. Thus uncertainty is represented only by "don't know" answers up to 1990, and by "probably yes/probably not/don't know" thereafter. The resulting discontinuity in the time series of intentions 1979-2005/7 is seen in Figure 2. On these separate definitions, women were appreciably more uncertain from 1991 onwards than before. Between $9 \%$ and $14 \%$ are classified uncertain in 1979-90 compared with $26 \%-31 \%$ thereafter, with the "don't knows" dropping to $1-2 \%$. Since it is unlikely that there was a step change in the level of uncertainty in 1991, the data strongly suggest that the coding and administration of the question up to 1990 resulted in an understatement of the level of uncertainty, and a corresponding overstatement of apparently certain responses, whether "yes" or "no". The sharp rise in uncertain responses in 1991 indicates a greater readiness to acknowledge unsure fertility intentions when an uncertain answer option is offered explicitly than when respondents have to volunteer one of their own accord, a phenomenon 
noted in other contexts as well (Kaufmann et al. 1997; Krosnick 1999). Surveys that do not provide explicit uncertainty precodes for intentions/expectations questions, and possibly also preference questions, may therefore understate the prevalence of uncertainty.

\section{Individual level factors associated with uncertainty}

\subsection{Analysis}

To assess how the variation in fertility intentions, and particularly in uncertainty, is associated with individual characteristics we use a multinomial logistic regression. The dependent variable is fertility intentions according to the first definition discussed above, that is the response - "yes", "probably yes", "probably not" or "no" - to the question whether a woman expects to have a (further) birth, regardless of the expected timing of any birth. The "don't know" category is dropped from the multinomial regression; it is too small for separate analysis, being just $0.8 \%$ of the $1991-2007$ sample analysed, and there is no rationale for combining it with any other response. The independent variables included for both groups are time period, age, partnership status, number of marriages, educational qualifications, socio-economic group and country of birth, and for parous women, parity and duration since most recent birth. All variables are entered in categorical form. Women aged $42-44$ are omitted from the analysis, as the frequency of "no" responses is close to $100 \%$ at these ages.

The sample analysed consists of women aged under 42 who answered the Family Information (FI) section of the GHS and who had valid values on all variables used in the analysis. Overall, 51,104 women under 42 were eligible for the FI section in 1991-2005/7, of whom 47,330 (92.6\%) completed the FI section $(18,616$ childless and 28,714 of parity $1+)$. Of these $2.8 \%$ overall $-3.1 \%$ of childless women and $2.7 \%$ of mothers - were excluded because of missing values on one or more variables in the present analysis. Descriptive statistics for this sample are given in Table 3. 
Table 3:

Sample distributions on variables used in multinomial logistic regression. Women aged < 42, unweighted. Great Britain, GHS 1991-2005/7

\begin{tabular}{|c|c|c|c|c|c|}
\hline & & \multicolumn{2}{|c|}{ Childless women } & \multicolumn{2}{|c|}{ Women of parity $1+$} \\
\hline & & $\mathbf{N}$ & $\%$ & $\mathbf{N}$ & $\%$ \\
\hline \multirow[t]{4}{*}{ Intentions } & Probably yes & 5,527 & 30.6 & 3,211 & 11.5 \\
\hline & Probably not & 2,002 & 11.1 & 4,164 & 14.9 \\
\hline & Yes & 7,979 & 44.2 & 3,125 & 11.2 \\
\hline & No & 2,530 & 14.0 & 17,449 & 62.4 \\
\hline \multirow[t]{5}{*}{ Period } & 1991-93 & 4,443 & 24.6 & 6,999 & 25.0 \\
\hline & $1994-96$ & 4,057 & 22.5 & 6,751 & 24.2 \\
\hline & $1998,2000-01$ & 3,593 & 19.9 & 5,559 & 19.9 \\
\hline & $2002-04$ & 3,794 & 21.0 & 5,528 & 19.8 \\
\hline & 2005-07 & 2,151 & 11.9 & 3,112 & 11.1 \\
\hline \multirow[t]{6}{*}{ Age } & $18-19$ & 2,372 & 13.2 & 277 & 1.0 \\
\hline & $20-24$ & 5,463 & 30.3 & 2,145 & 7.7 \\
\hline & $25-29$ & 4,612 & 25.6 & 4,869 & 17.4 \\
\hline & $30-34$ & 3,096 & 17.2 & 8,009 & 28.7 \\
\hline & $35-39$ & 1,919 & 10.6 & 9,014 & 32.3 \\
\hline & $40-41$ & 576 & 3.2 & 3,635 & 13.0 \\
\hline \multirow{4}{*}{$\begin{array}{l}\text { Open interval } \\
\text { (time since } \\
\text { previous birth) }\end{array}$} & $0-2$ years & & & 9,845 & 35.2 \\
\hline & $3-5$ years & & & 6,560 & 23.5 \\
\hline & $6-9$ years & & & 5,876 & 21.0 \\
\hline & $10+$ years & & & 5,668 & 20.3 \\
\hline \multirow[t]{3}{*}{ Parity } & 1 & & & 8,786 & 31.4 \\
\hline & 2 & & & 12,160 & 43.5 \\
\hline & $3+$ & & & 7,003 & 25.1 \\
\hline \multirow[t]{3}{*}{ Living with... } & Spouse & 4,112 & 22.8 & 18,160 & 65.0 \\
\hline & Partner & 3,602 & 20.0 & 3,140 & 11.2 \\
\hline & Alone & 10,324 & 57.2 & 6,649 & 23.8 \\
\hline \multirow{6}{*}{ Qualifications } & Degree & 4,112 & 22.8 & 2,869 & 10.3 \\
\hline & Other post-A level & 1,784 & 9.9 & 2,773 & 9.9 \\
\hline & A level & 4,596 & 25.5 & 3,451 & 12.3 \\
\hline & $\mathrm{O} / \mathrm{CSE} /$ cler. & 6,126 & 34.0 & 12,455 & 44.6 \\
\hline & Other & 393 & 2.2 & 706 & 2.5 \\
\hline & None & 1,027 & 5.7 & 5,695 & 20.4 \\
\hline \multirow[t]{3}{*}{ No. of marriages } & 0 & 13,051 & 72.4 & 5,410 & 19.4 \\
\hline & 1 & 4,676 & 25.9 & 20,191 & 72.2 \\
\hline & $2+$ & 311 & 1.7 & 2,348 & 8.4 \\
\hline \multirow[t]{5}{*}{ SEG } & Employers & 4,866 & 27.0 & 6,781 & 24.3 \\
\hline & Intermediate & 6,897 & 38.2 & 9,076 & 32.5 \\
\hline & PS \& skilled & 4,448 & 24.7 & 9,515 & 34.0 \\
\hline & Unskilled & 610 & 3.4 & 1,611 & 5.8 \\
\hline & Other & 1,217 & 6.7 & 966 & 3.5 \\
\hline \multirow[t]{2}{*}{ Country of birth } & UK & 16,254 & 90.1 & 25,285 & 90.5 \\
\hline & Other & 1,784 & 9.9 & 2,664 & 9.5 \\
\hline Total & & 18,038 & 100 & 27,949 & 100 \\
\hline
\end{tabular}




\subsection{Findings}

The multinomial model is fitted separately for women with and without children. The coefficients of the model for childless women and for women of parity $1+$ are given in Appendix Tables A1 and A2, respectively. The reference response is "yes". Thus, the coefficients in the column for each response represent the log odds of that response relative to answering "yes" and to the reference category for the variable in question. For clarity of interpretation, we present the estimated probabilities of each response (yes, probably yes, probably not, no) from these models graphically in Figures 3 and 4, for women with specified characteristics but at the sample average on all other variables. As all variables in the model are categorical, the estimated probability of a response for each category of a specified variable is calculated with other factors fixed at the sample distribution for childless women and mothers, respectively. The estimated probability of each response for childless women as a whole is shown by a bold horizontal line in each panel of Figure 3: thus an estimated $44 \%$ of childless women who are at the average (among the childless) on all other characteristics answered "yes", 30\% "probably yes", 11\% "probably not" and 14\% "no". In Figure 4, the corresponding estimates for mothers are $11 \%, 12 \%, 15 \%$ and $62 \%$. Thus, the overall estimated probability of an uncertain response ("probably yes" or "probably not") among women with average characteristics is four in ten among the childless and one in four among mothers.

Considered as a whole, the results of the multinomial analyses show that intentions vary largely with demographic factors and life stage - age, partnership status, parity and duration since previous birth. The age effect is substantial, and constitutes the dominant effect among both childless women and mothers. Partnership status effects are more pronounced among childless women than among mothers, and largely in relation to "yes" or "probably yes" responses; the major contrast is between the married and those without a partner, with cohabiters generally intermediate between them. Among mothers, both parity and time since previous birth have strong effects, particularly in differentiating the probability of a "no" response. The estimated effects of other factors in the models are either not significant or relatively minor. There are some significant period coefficients, but variation in intentions with time period is slight. Educational qualifications have relatively small effects, though the lesser frequency of "no" responses among childless women with degree level qualifications, net of other factors, is of interest.

Looking at these findings a little more detail, we saw in Table 2 above that half of all childless women in their early thirties are uncertain about their future childbearing. Figure 3 reveals that to the mid-30s, the uncertainty is mainly positive, but that this shifts gradually, with "probably not" continuing to rise to the late $30 \mathrm{~s}$. The pattern of response by age among childless women is suggestive of a move from "yes" in the late 20 s to "probably yes" in the early thirties, to "probably not" in the mid to late thirties, and finally to "no". Of course, with 
rising age the childless are progressively more select, and so this may not be the sequence experienced by individuals; such change with age at the individual level cannot be inferred from cross-sectional data. The persistence of some, albeit increasingly tentative, thoughts of childbearing among a sizeable minority into the early 40 s is noteworthy. At age 41 , under the present model, an estimated $29 \%$ of childless women with average characteristics are uncertain about their future childbearing, though the large majority of them think they probably will not have a child. Among mothers, the age effect varies little up to the late 20 s but the probability of a positive intention, whether "yes" or "probably yes", declines with age from the late twenties on. The probability of a "no" response rises correspondingly, but "probably not" is distinctive, its frequency changing rather less with age, given average characteristics.

Among the childless, the partnership status is strongly associated with intention, those living with a spouse being most likely and those living alone least likely to intend a child. In all, $37 \%$ of childless women with average characteristics who live alone are predicted as intending a future birth and $40 \%$ as thinking it probable, in contrast with $60 \%$ and $27 \%$ of those living with a spouse. Women without a partner are, correspondingly, less certain of their childbearing prospects. Childless women living alone are more uncertain than those living with a partner, who in turn are less sure than married women, the adjusted proportions of "probably" answers being 53\%, 39\% and 33\%, respectively, given average characteristics. Partner effects are less pronounced among mothers - a reasonable result.

Among mothers, sizeable effects are seen both for parity and duration since previous birth. As would be expected in view of the high proportions progressing from first to second birth, women of parity 1 are much more likely to intend a further birth than those of higher parities. Nevertheless, the level of uncertainty among women with one child is noteworthy: $38 \%$ of mothers of parity 1 with average characteristics are estimated to be unsure about future childbearing, in contrast with $23 \%$ and $16 \%$ of those of parities 2 and $3+$, respectively. The duration effects are also much as we might expect, with both positive intentions and uncertainty declining with time since the previous birth. Because of the much greater proportions proceeding from a first to a second birth compared with higher-order progressions, we hypothesised that parity and duration since previous birth would interact. A significant interaction of this kind is indeed found and is shown in Figure S1 (online supplement). The principal feature of interest is the profile of intentions after the first compared with second and later births (always remembering that these are cross-sectional rather than longitudinal data). Overall uncertainty increases in the six years after first birth, rather than declining as it does following later births. However, we cannot tell from these cross-sectional data whether individual women become more uncertain as time goes by after the first birth, or whether the finding reflects a progressively more select group of women. At each duration following a first birth women are more 
highly selected with respect to progression to a further birth than at the same duration after second and later births. In the present sample, just $40 \%$ of women who had a first birth between three and six years prior to the survey had not had a further birth by the time of the survey, compared with $70 \%$ of those who had a second, and $75 \%$ of those who had a third at the same duration before the survey. The profile of uncertainty by duration since first birth may thus stem from selection of those initially uncertain or those who have become so, whether owing to problems of fecundity or for other reasons. The question can only be fully examined with longitudinal data. It is worth investigating in view of the substantial excess of one-child families over the proportion anticipated at younger ages found in an earlier analysis of these data (Ní Bhrolcháin et al. 2010).

We saw earlier in Table 2 and associated discussion that the level and age profile of uncertainty varies substantially according to how uncertainty is defined. To examine the impact of definitional change in a multivariate context, two further multinomial logistic regressions have been fitted with fertility intentions according to definition 3 above as the dependent variable: that is, the uncertain include those answering probably yes, probably not, or don't know to the question on a future birth and those who answered yes but expected that birth to be three years or more into the future. The estimated probabilities are shown in Figures S2 and S3 (online supplement). The pattern of effects for mothers in supplement Figure S3 is broadly similar to that seen according to the first definition in Figure 4 above. However, the estimates for the "yes" and "probably yes" responses among the childless (Figure S2, online supplement) diverge in two prominent ways from those seen earlier in Figure 3. First, the age effects differ, with the probability of a "yes" response first increasing and then declining by age, unlike the previous pattern of approximate stability followed by decline. The age pattern of the "probably yes" response differs markedly from Figure 3 - with a steady decline throughout the age range, quite unlike the previous profile of stability. ${ }^{3} \mathrm{~A}$ second point is that differentials by educational qualifications are more pronounced than in the earlier analysis, particularly in the "probably yes" response. These results indicate that the definition of uncertainty matters not only in respect of the level of uncertainty, but also as regards the individual-level variation in fertility intentions in general.

3 The sharp peak for the "yes" and the dip for the "probably yes" categories at age 28 reflects in all likelihood heaping at age 30 . That is, many 28 year olds who answered "yes" will have given 30 as their expected age at (next) birth; their expected time to next birth will therefore have been two years and they will have remained in the "yes" group in definition 3. Digit preference reflects a lack of certainty and so this feature suggests that some women specifying a wait to next birth of less than three years should be classified as uncertain. 
Figure 3:

Estimated probabilities of responses on fertility intentions, for women with specified characteristics and at the sample mean on all other variables. Childless women aged $<42$, weighted. GB, GHS 1991-2005/7

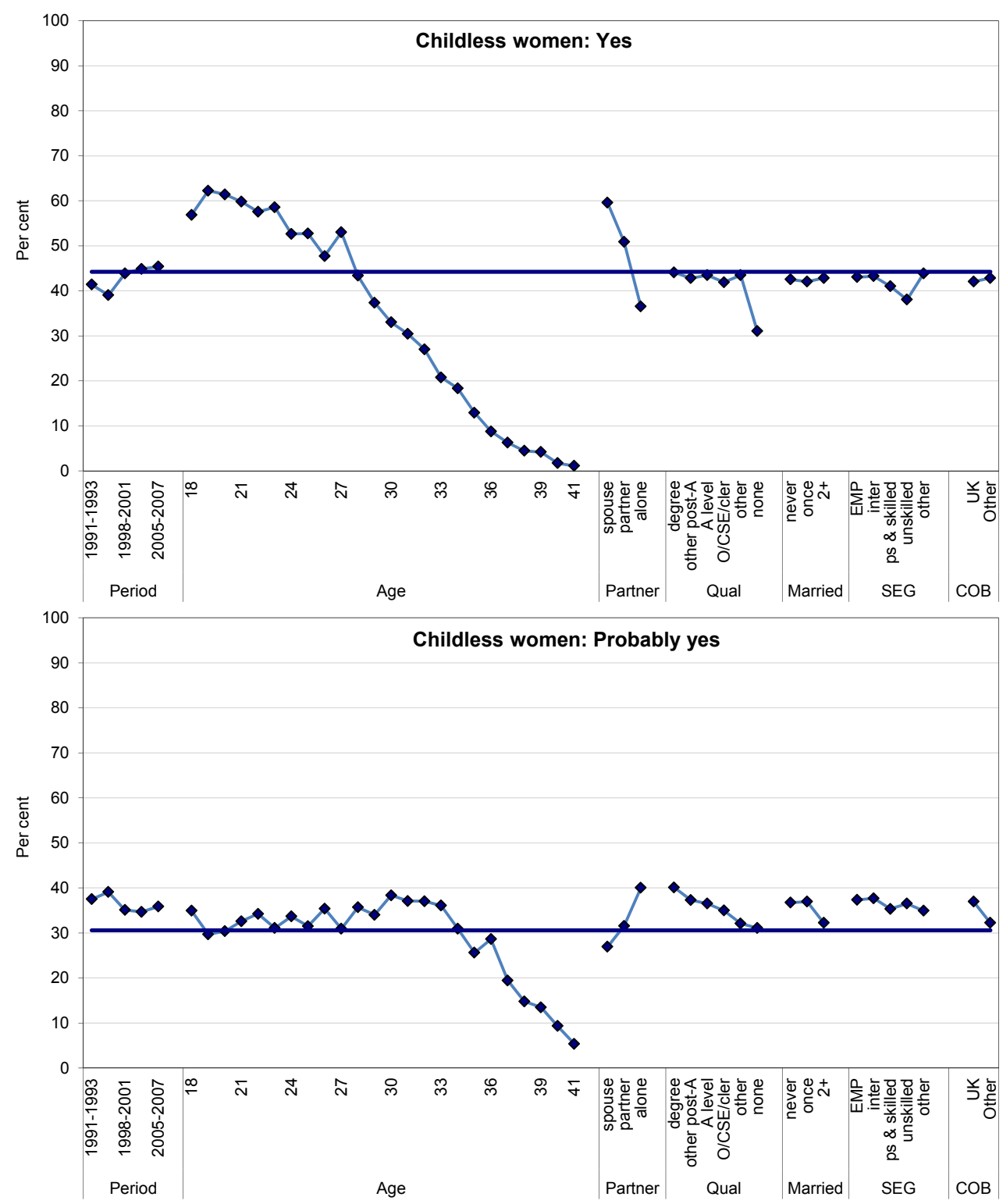

Figure continued on the next page 
Figure 3 (continued)
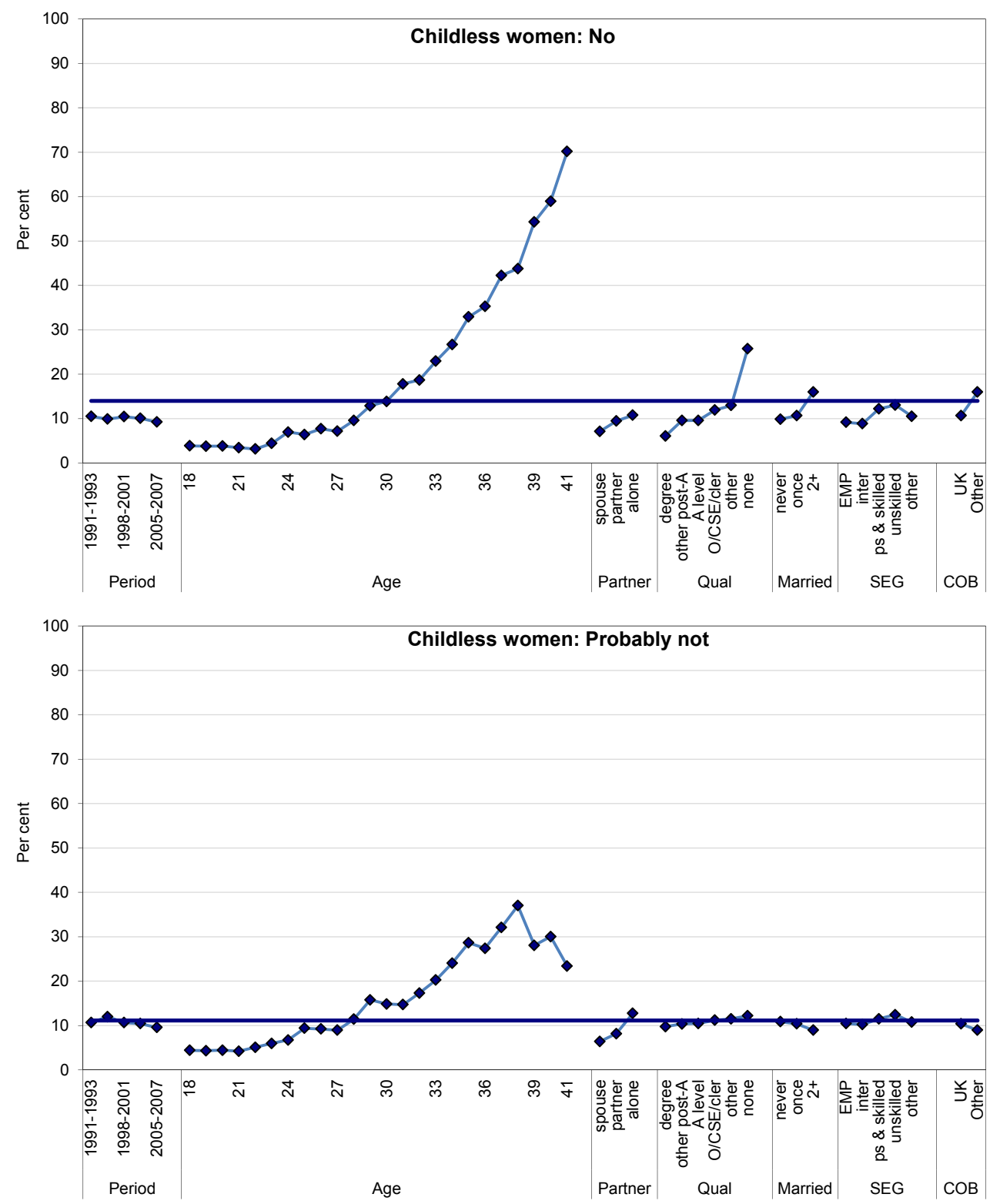
Figure 4:

Estimated probabilities of responses on fertility intentions, for women with specified characteristics and at the sample on all other variables. Women of parity $1+$, aged $<42$, weighted. GB, GHS 1991-2005/7
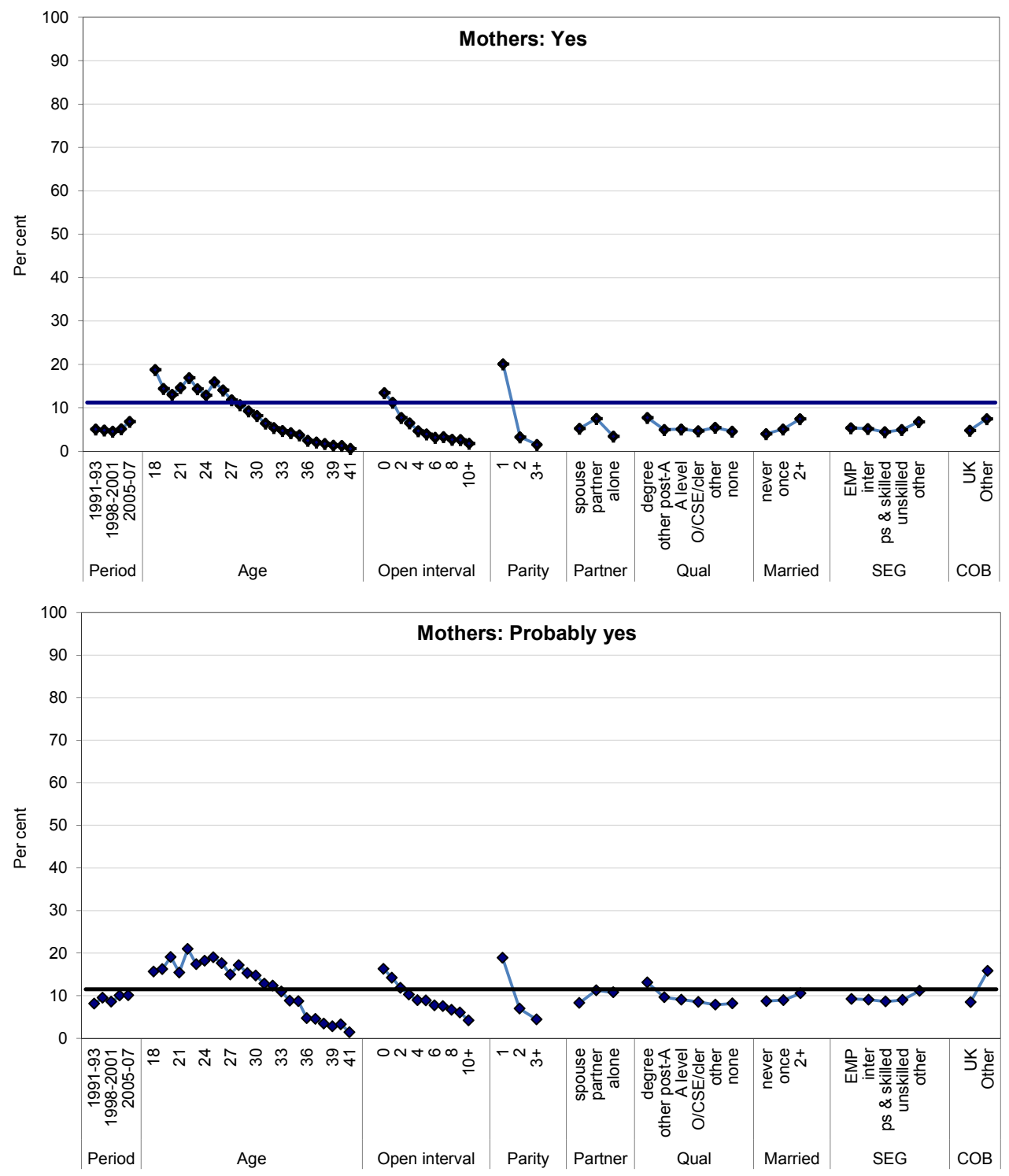

Figure continued on the next page 
Figure 4 (continued)
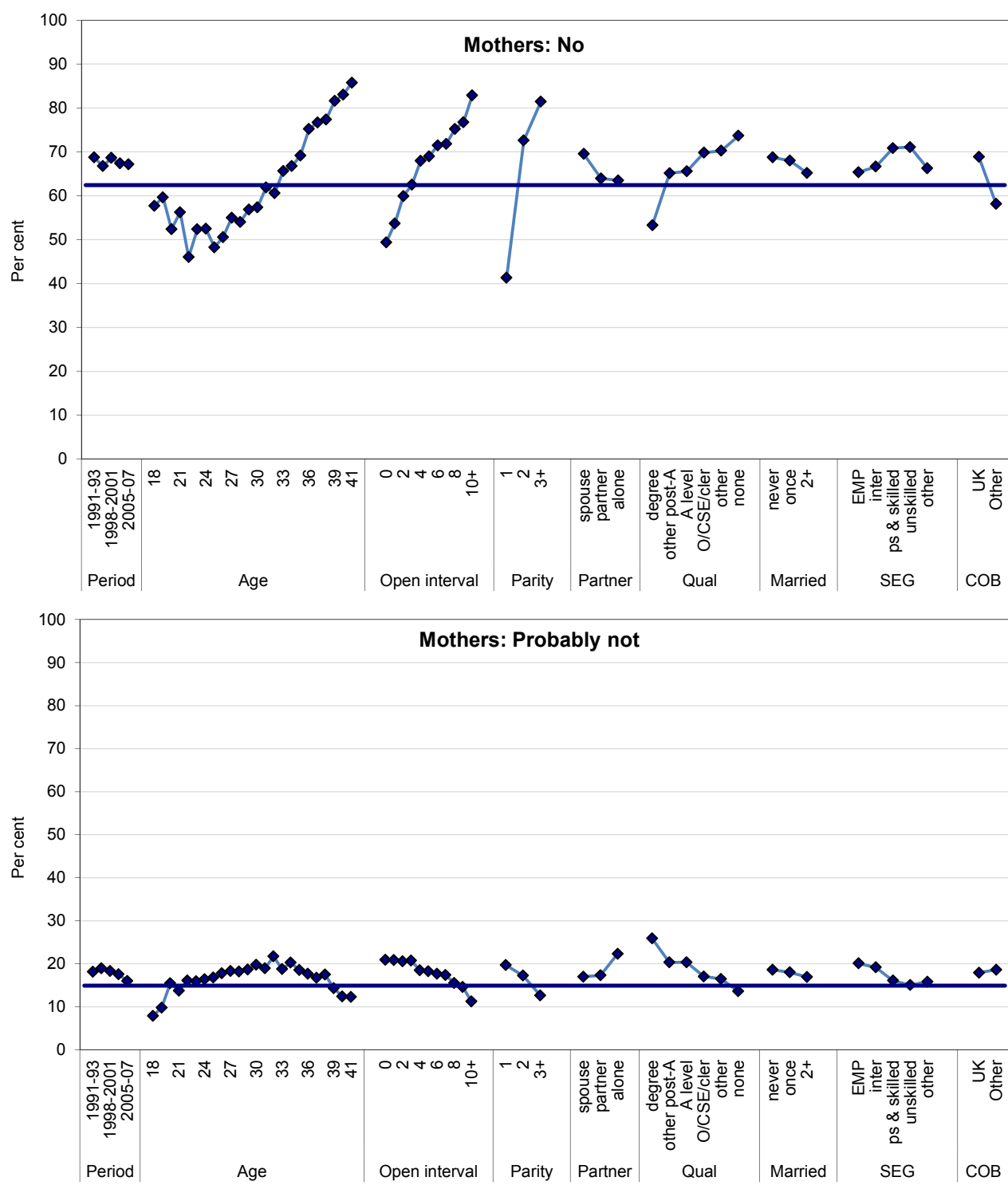


\section{Discussion}

The aims of the present article have been threefold: to draw attention to the relatively high prevalence of uncertainty about prospective childbearing both in Britain and in other developed countries; to show that the level of uncertainty varies substantially both with survey question format and with alternative definitions; and to identify individual-level factors associated with uncertain fertility intentions. Uncertainty among women of childbearing age in Britain has been substantial in recent decades, with $30 \%$ of women overall $(39 \%$ at ages under 35) not sure about whether they will have a (further) birth. And, just as fertility intentions are not binary (Morgan 1981), so too the level of certainty is unlikely to be dichotomous. A broader definition of uncertainty that includes women who expect a (further) birth in $3+$ years' time raises the estimated proportion uncertain very substantially. On this extended definition, the large majority of the youngest women - $83 \%$ of women under 25 and $89 \%$ of the childless of this age - are unsure about their prospective childbearing. Importantly, the inclusive definition of uncertainty also presents a somewhat different profile of effects in the multinomial model, particularly in respect of age.

The substantial levels of uncertainty in fertility intentions found in the GHS are not an isolated case. We show elsewhere that considerable uncertainty is found in a range of developed country fertility surveys over four decades (Ní Bhrolcháin and Beaujouan forthcoming: Table 1). Prevalence is rarely below $10 \%$, and where this low, it is generally among specific sub-groups rather than overall. Of the 33 studies we identified, 23 record a level of uncertainty of $20 \%$ or more and 18 a level of $30 \%$ or more, either for the sample as a whole, or in at least one subgroup (uncertainty is, in our compilation, based on a variety of types of question and response codes). The figure of $40 \%$ found on our first definition at ages up to the mid 30s in the GHS is matched or exceeded by the overall figures of several studies: Rindfuss et al. (1988) for men, Thomson (1997), Thomson and Hoem (1998), Toulemon and Testa (2005), Testa and Toulemon (2006) and Sobotka and Testa (2008). Overall proportions uncertain in the range $20 \%-40 \%$ are reported by Westoff et al. (1961), Cartwright (1976), Westoff and Ryder (1977), Dunnell (1979), Morgan (1981), Oakley (1981), Berent (1983), Morgan (1985), Rindfuss et al. (1988) for women, Schoen et al. (1999), Kneale and Joshi (2008), Sobotka and Testa (2008) and Vignoli and Régnier-Loilier (2010). However, the estimated level of certainty in fertility intentions depends on whether uncertain answer options are explicitly available (Kaufmann et al. 1997; Krosnick 1999). We saw that providing explicit uncertainty precodes, and a probe question, in an otherwise unchanging survey context, almost triples the reporting of uncertain fertility intentions in the space of one year, 1990-1991, from $9 \%$ to $28 \%$. Hence, previous surveys that did not provide uncertain answer options explicitly may have underestimated the prevalence of uncertain fertility intentions and preferences. 
Comparable studies, then, by and large confirm the picture presented by the GHS of considerable uncertainty regarding fertility intentions. The prevalence of uncertainty is substantially higher than is generally recognised. But markedly different estimates of the prevalence of uncertainty result, as we saw above, both from differences in question format and from alternative definitions of uncertainty. Questions of the kind asked in the GHS are in wide use in demographic surveys, and have been so for decades, but their validity, in the sense of how well they measure their target, is unknown. Coombs's (1974: 588) assessment that "[m] ost measures in the field of family size preferences utilize ad hoc empirical indices with no theoretical basis" remains true, nearly 40 years on. Furthermore, most measures of fertility intentions/expectations have not been constructed or evaluated according to psychometric criteria (see e.g. Zabin 1999). Notable exceptions are the scales devised by Coombs herself, and the work of Schaeffer and Thomson (1992) and Thomson and Brandreth (1995).

Systematic research, both qualitative and quantitative, is therefore required to explore concepts and to develop and validate measures of fertility expectations in general, together with indicators of certainty and uncertainty. There are several resources on which such work could draw. Schaeffer and Thomson's (1992) study, providing ample evidence that routine survey questions are insufficient to capture the quality and degree of respondents' uncertainty, together with Thomson and Brandreth (1995), would make an excellent starting point. Recent research on improving measures of pregnancy intendedness is a further resource (Kaufmann et al. 1997; Bachrach and Newcomer 1999; Stanford et al. 2000; Barrett et al. 2004; Stevens-Simon et al. 2005; Santelli et al. 2009; Schwartz et al. 2010). Third, another approach to measuring expectations and intentions is using probabilistic questions to elicit an assessment of level of certainty in continuous rather than classified form (Burden 1997; Manski 2004; Delavande 2008).

How confident can we be that the uncertainty reported in demographic surveys is genuine rather than the result of inadequate question design or superficial responses? Several sources of evidence substantiate the reality of reported uncertainty. First, follow-up studies consistently find that women/couples unsure about their fertility intentions are less likely to carry them out than those who are more certain: women/couples who expect "probably" to have a birth are less likely to have one and those who "probably" do not expect a birth are more likely to not have one, than those who declare more certain intentions (Cartwright 1976; Woolf and Pegden 1976; Westoff and Ryder 1977; Thomson 1997; Thomson and Hoem 1998; Schoen et al. 1999; Toulemon and Testa 2005; Testa and Toulemon 2006). Second, evidence that pregnancy intentions can be suffused with ambiguity and ambivalence has been accumulating for decades. Qualitative and quantitative studies both in demography and in reproductive health bear out the existence of much uncertainty. In a major demographic study of uncertainty in a developed-country context, Schaeffer and Thomson (1992) carried out a content analysis of semi- 
structured interviews, with the explicit aim of investigating uncertain fertility motivations in depth. Their findings provide compelling evidence both of the frequency of uncertainty and of its plurality, showing that it encompasses several subjective states: neutral feelings about prospective childbearing, lack of clarity, ambivalence and indecision, either singly or in combination. ${ }^{4}$ Research on pregnancy intentions amply bears out these points. Cartwright (1988) reported that $27 \%$ of recent mothers said the pregnancy was unintended, and that of these, $37 \%$ reported that they were pleased to be pregnant at the time $(23 \%$ were using a method and $13 \%$ were not). On the other hand, $14 \%$ of those saying they intended the pregnancy had been using a contraceptive method. In a study based on the 1995 US National Survey of Family Growth, Trussell et al. (1999) reported that $31 \%$ of pregnancies resulting from a contraceptive failure were described as "intended", that many of those becoming pregnant while using a method considered the timing to be "about right", and that $25 \%$ of those with unintended pregnancies were either "happy" or "very happy" to be pregnant. This study together with related evidence that reported intention can change during pregnancy (Joyce et al. 2000; Poole et al. 2000), that the concept of planning is often poorly understood (Moos et al. 1997; Barrett and Wellings 2002; Kendall et al. 2005), and that pregnancy intentions are subject to much ambivalence (Sable and Libbus 2000; Zabin et al. 2000; Schwarz et al. 2007; Kavanaugh and Schwarz 2009; Schwartz et al. 2010) has prompted considerable reflection on the complexity of intentionality in relation to pregnancy and fertility control (Bachrach and Newcomer 1999; Luker 1999; Zabin 1999; Santelli et al. 2003; Esacove 2008; Barber et al. 2010; Greil and McQuillan 2010). A vivid illustration of the ambiguity of intentional states is McQuillan et al.'s (2010) finding that $23 \%$ of a sample of sexually active women were neither trying to become pregnant nor trying to avoid pregnancy, but were "okay either way". A reasonable conclusion from this body of evidence, both qualitative and quantitative, is that while the reality of uncertain pregnancy intentions can hardly be doubted, the utility of traditional approaches to measuring intentions certainly can. It seems reasonable to suppose that this applies also to fertility intentions as more broadly conceptualised in demography.

There is much convergent evidence that uncertain answers to survey questions on fertility expectations reflect genuine uncertainty on the part of respondents. We argue elsewhere that uncertainty is a reasonable response to the many contingencies and unknowns that people encounter throughout the life cycle, whether stemming from their personal circumstances or from the aggregate social

$4 \quad$ A demographic study in a developing country setting finds widespread and insistent uncertainty among young educated women in Cameroon about the future in general, and fertility expectations in particular (Johnson-Hanks 2005). The impression conveyed by this ethnographic account contrasts sharply with the relatively low frequency of uncertainty recorded by the DHS. In the Cameroon DHS rounds of 1991, 1998, and 2004, 10\%-15\% were classified, via standard questions, as uncertain about ideal family size, having given a non-numeric response, and under $15 \%$ were recorded as uncertain about whether they expected a further birth. 
and economic environment. It is thus a rational response to the developing life course (Ní Bhrolcháin and Beaujouan forthcoming). If correct, this perspective has a number of implications for current approaches to reproductive decisions. First, if as many as four in five women under 25 are unsure about their fertility intentions (and three in five women under 35) this may be part of the explanation both for the instability of intentions across the life course and for their weak predictive power. Thus, the role that uncertainty plays in contributing both to instability and to imperfect prediction needs investigation. Second, the existence of substantial uncertainty throughout the entire childbearing period, but especially at the youngest ages, has important implications for concepts and theory. Current ideas in demography about individuals' reproductive choices assume the existence of clear preferences and intentions, and that decisions are taken either according to a full-blown rational choice model or in a means-end framework of some kind. The existence of substantial uncertainty is inconsistent with such accounts. Morgan $(1981,1982)$ noted that uncertainty is inherent in the family formation process but existing theoretical perspectives on childbearing, whether economic (Becker 1981) or social-psychological (Ajzen 1991; Heckhausen and Schulz 1995; Miller and Pasta 1995; Miller et al. 2004) have little to say about the phenomenon. We present in greater detail elsewhere a new theoretical approach to fertility preferences and intentions (Ní Bhrolcháin and Beaujouan forthcoming), suggesting that these can be coherently interpreted in the framework of constructed preferences (Lichtenstein and Slovic 2006). On this hypothesis, preferences and intentions are not well-articulated at younger ages, but are constructed in interaction with experience and the developing life-course. Much further work is needed to explore the process by which reproductive preferences and intentions are formed and how the constructive preferences perspective helps to elucidate fertility dynamics at both individual and aggregate levels. Current developments in the field include the ideas of Morgan and Bachrach (2011) and Johnson-Hanks et al. (2011 forthcoming) who draw on several disciplines to bring a broad-ranging perspective to childbearing decisions, with which the approach developed here is entirely consonant.

\section{Acknowledgements}

We thank Allan Hill and two anonymous reviewers for helpful comments on an earlier draft of this article, and James Brown for advice. The CPC GHS time series datafile on which this article is based was constructed in collaboration with Dr Ann Berrington and with the assistance of Mark Lyons-Amos. We thank the Demographic Analysis Branch and the General Lifestyle Survey Branch of the Office for National Statistics for their help in clarifying various data issues. This research is funded by ESRC Grant number RES-625-28-0001. The Centre for Population Change (CPC) is a joint initiative between the University of 
Southampton and a consortium of Scottish Universities in partnership with ONS and GROS. The findings, interpretations and conclusions expressed in this article are entirely those of the authors and should not be attributed in any manner to ONS or GROS. The General Household Survey is conducted by the Office for National Statistics. Access to the data is provided by the UK Data Archive.

\section{References}

Ajzen, I. 1991. The theory of planned behavior. Organizational Behavior and Human Decision Processes 50(2): 179-211.

Ali, R., J. Greer, D. Matthews, L. Murray, S. Robinson and G. Sattar 2008. General household survey 2006. London: Office for National Statistics. Available at http://www.statistics.gov.uk/statbase/product.asp?vlnk=5756, accessed August 2010.

Bachrach, C.A. and S. Newcomer 1999. Intended pregnancies and unintended pregnancies: Distinct categories or opposite ends of a continuum? Family Planning Perspectives 31(5): 251-252.

Barber, J.S., W.B. Miller and H.H. Gatney 2010. The desire to become pregnant and the desire to avoid pregnancy: ambivalence, indifference, pronatalism, and antinatalism. Presented at the international conference "From Intentions to Behaviour: Reproductive Decision-Making in a Macro-Micro Perspective", Vienna, December 2010.

Barrett, G., S.C. Smith and K. Wellings 2004. Conceptualisation, development, and evaluation of a measure of unplanned pregnancy. Journal of Epidemiology and Community Health 58(5): 426-433.

Barrett, G. and K. Wellings 2002. What is a "planned" pregnancy? Empirical data from a British study. Social Science and Medicine 55(4): 545-557.

Barton, J. 2001. Developing a weighting and grossing system for the general household surveys in the United Kingdom. Survey Methododology Bulletin 49: 15-26.

Beaujouan, É., J.J. Brown and M. Ní Bhrolcháin 2011. Reweighting the General Household Survey 1979-2007. Population Trends 145: 119-145.

Becker, G.S. 1981. A treatise on the family. Cambridge, Mass.: Harvard University Press.

Berent, J. 1983. Family size preferences in Europe and USA: Ultimate expected number of children. WFS Comparative Studies 26.

Berrington, A. 2004. Perpetual postponers? Women's, men's and couple's fertility intentions and subsequent fertility behaviour. Population Trends 117: 9-19.

Blake, J. 1966. Ideal family size among white americans: A quarter of a century's evidence. Demography 3(1): 154-173.

Bongaarts, J. 2002. The end of the fertility transition in the developed world. Population and Development Review 28(3): 419-443.

Bumpass, L. and C.F. Westoff 1969. The prediction of completed fertility. Demography 6(4): 445-454.

Burden, B.C. 1997. Deterministic and probabilistic voting models. American Journal of Political Science 41(4): 1150-1169.

Cartwright, A. 1976. How many children? London: Routledge \& Kegan Paul.

Cartwright, A. 1988. Unintended pregnancies that lead to babies. Social Science and Medicine 27(3): 249-254. 
Cartwright, A. and W. Wilkins 1976. Changes in family building plans: a follow up study to "How many children?". Studies on Medical and Population Subjects, OPCS 33.

Coombs, L.C. 1974. Measurement of family-size preferences and subsequent fertility. Demography 11(4): 587-611.

Delavande, A. 2008. Measuring revisions to subjective expectations. Journal of Risk and Uncertainty 36(1): 43-82.

Dunnell, K. 1979. Family formation 1976. London: H.M.S.O.

Esacove, A. 2008. Making sense of sex: rethinking intentionality. Culture Health \& Sexuality 10(4): 377-390.

Freedman, R., D.S. Freedman and A.D. Thornton 1980. Changes in fertility expectations and preferences between 1962 and 1977 - their relation to final parity. Demography 17(4): 365-378.

Freedman, R., P. Whelpton and A. Campbell 1959. Family planning, sterility and population growth. New York: McGraw Hill.

Goldstein, J., W. Lutz and M.R. Testa 2003. The emergence of sub-replacement family size ideals in Europe. Population Research and Policy Review 22(5-6): 479-496.

Greil, A.L. and J. McQuillan 2010. "Trying" times: Medicalization, intent, and ambiguity in the definition of infertility. Medical Anthropology Quarterly 24(2): 137-156.

Hagewen, K.J. and S.P. Morgan 2005. Intended and ideal family size in the United States, 1970-2002. Population and Development Review 31(3): 507-527.

Hauser, P.M. 1967. Review: 'Family planning and population programs': a book review article. Demography 4(1): 397-414.

Hayford, S.R. and S.P. Morgan 2008. Religiosity and fertility in the United States: the role of fertility intentions. Social Forces 86(3): 1163-1188.

Heckhausen, J. and R. Schulz 1995. A life-span theory of control. Psychological Review 102(2): 284-304.

Johnson-Hanks, J. 2005. When the future decides - uncertainty and intentional action in contemporary Cameroon. Current Anthropology 46(3): 363-385.

Johnson-Hanks, J., C. Bachrach, S.P. Morgan and H.-P. Kohler 2011. Understanding family change and variation: toward a theory of conjunctural action. New York: Springer.

Joyce, T., R. Kaestner and S. Korenman 2000. The stability of pregnancy intentions and pregnancy-related maternal behaviors. Maternal and Child Health Journal 4(3): 171-178.

Kaufmann, R., L. Morris and A.M. Spitz 1997. Comparison of two question sequences for assessing pregnancy intentions. American Journal of Epidemiology 145(9): 810-816.

Kavanaugh, M.L. and E.B. Schwarz 2009. Prospective assessment of pregnancy intentions using a single versus a multi-item measure. Perspectives on Sexual and Reproductive Health 41(4): 238-243.

Kendall, C., A. Afable-Munsuz, I. Speizer, A. Averya, N. Schmidt and J. Santelli 2005. Understanding pregnancy in a population of inner-city women in New Orleans results of qualitative research. Social Science and Medicine 60: 297-311.

Kiser, C.V. 1967. Review: the growth of American families studies: an assessment of significance. Demography 4(1): 388-396.

Kneale, D. and H. Joshi 2008. Postponement and childlessness: evidence from two British cohorts. Demographic Research 19: 1935-1968.

Krosnick, J.A. 1999. Survey research. Annual Review of Psychology 50: 537-567. 
Lee, R.D. 1980. Aiming at a moving target: period fertility and changing reproductive goals. Population Studies 30(2): 205-226.

Lee, R.D. 1981. A model for forecasting fertility from birth-expectations data. In Predicting fertility. Demographic studies of birth expectations, ed. G.E. Hendershot and P.J. Placek, 75-99. Lexington, Mass.: Lexington Books.

Lewis-Faning, E. 1949. Papers of the Royal Commission on Population Volume 1. Report on an enquiry into family limitation and its influence on human fertility during the past fifty years. London: H.M.S.O.

Lichtenstein, S. and P. Slovic, eds. 2006. The construction of preference. Cambridge: Cambridge University Press.

Liefbroer, A.C. 2009. Changes in family size intentions across young adulthood: a lifecourse perspective. European Journal of Population 25(4): 363-386.

Luker, K.C. 1999. A reminder that human behavior frequently refuses to conform to models created by researchers. Family Planning Perspectives 31(5): 248-249.

Manski, C.F. 2004. Measuring expectations. Econometrica 72(5): 1329-1376.

McQuillan, J., A.L. Greil and K.M. Shreffler 2010. Pregnancy intentions among women who do not try: focusing on women who are okay either way. Maternal and Child Health Journal 15(2): 178-187.

Miller, W.B. and D.J. Pasta 1995. Behavioral intentions - which ones predict fertility behavior in married-couples. Journal of Applied Social Psychology 25(6): 530-555.

Miller, W.B., L.J. Severy and D.J. Pasta 2004. A framework for modelling fertility motivation in couples. Population Studies 58(2): 193-205.

Monnier, A. 1989. Fertility intentions and actual behaviour. a longitudinal study: 1974, 1979. Population 44(1): 237-259.

Moos, M.-K., R. Petersen, K. Meadows, C.L. Melvin and A.M. Spitz 1997. Pregnant women's perspectives on intendedness of pregnancy. Women's Health Issues 7(6): 385-392.

Morgan, S.P. 1981. Intention and uncertainty at later stages of childbearing: the United States 1965 and 1970. Demography 18(3): 267-285.

Morgan, S.P. 1982. Parity-specific fertility intentions and uncertainty -the United States, 1970 to 1976. Demography 19(3): 315-334.

Morgan, S.P. 1985. Individual and couple intentions for more children - a research note. Demography 22(1): 125-132.

Morgan, S.P. 2001. Should fertility intentions inform fertility forecasts?, The direction of fertility in the United States, Alexandria, Virginia 2001. Washington, D.C.: US Census Bureau.

Morgan, S.P. and C.A. Bachrach 2011. Is the Theory of Planned Behaviour an appropriate model for human fertility? Vienna Yearbook of Population Research Vol 9:11-18.

Morgan, S.P. and R. Chen 1992. Predicting childlessness for recent cohorts of American women. International Journal of Forecasting 8(3): 477-493.

Morgan, S.P. and H. Rackin 2010. The correspondence between fertility intentions and behavior in the United States. Population and Development Review 36(1): 91-118.

Murphy, M. 2009. Where have all the children gone? Women's reports of more childlessness at older ages than when they were younger in a large-scale continuous household survey in Britain. Population Studies 63(2): 115-133.

Ní Bhrolcháin, M. and É. Beaujouan (forthcoming). How real are reproductive goals?

Ní Bhrolcháin, M., É. Beaujouan and A. Berrington 2010. Stability and change in fertility intentions in Britain, 1991-2007. Population Trends 141: 1-23. 
Ní Bhrolcháin, M., É. Beaujouan and M. Murphy 2011. Sources of error in reported childlessness in a continuous British household survey. Population Studies 65: 305-318.

Noack, T. and L. Ostby 1985 . Fertility expectations: a short cut or dead-end in predicting fertility? Scandinavian Population Studies 7: 48-59.

Oakley, D. 1981. Reflections on the development of measures of childbearing expectations. In Predicting fertility. Demographic studies of birth expectations, ed. G.E. Hendershot and P.J. Placek, 11-26. Lexington, Mass.: Lexington Books.

Philipov, D. 2009. The effect of competing intentions and behaviour on short-term childbearing intentions and subsequent childbearing. European Journal of Population 25(4): 525-548.

Poole, V.L., J.S. Flowers, R.L. Goldenberg, S.P. Cliver and S. McNeal 2000. Changes in intendedness during pregnancy in a high-risk multiparous population. Maternal and Child Health Journal 4(3): 179-182.

Quesnel-Vallée, A. and S.P. Morgan 2003. Missing the target? Correspondence of fertility intentions and behavior in the US. Population Research and Policy Review 22(5-6): 497-525.

Rindfuss, R.R., S.P. Morgan and G. Swicegood 1988. First births in America. London: University of California Press.

Sable, M.R. and M.K. Libbus 2000. Pregnancy intention and pregnancy happiness: are they different? Maternal and Child Health Journal 191-196.

Santelli, J., R. Rochat, K. Hatfield-Timajchy, B.C. Gilbert, K. Curtis, R. Cabral, J.S. Hirsch, L. Schieve and Unintended Pregnancy Working Group 2003. The measurement and meaning of unintended pregnancy. Perspectives on Sexual and Reproductive Health 35(2): 94-101.

Santelli, J.S., L.D. Lindberg, M.G. Orr, L.B. Finer and I. Speizer 2009. Toward a multidimensional measure of pregnancy intentions: evidence from the United States. Studies in Family Planning 40(2): 87-100.

Sautory, O. 1993. La macro calmar: redressement d'un échantillon par calage sur marge. Documents de travail de la direction des statistiques démographiques et sociales F9310. www.insee.fr/fr/methodes/default.asp?page=outils/calmar/accueil_calmar.htm

Schaeffer, N.C. and E. Thomson 1992. The discovery of grounded uncertainty: developing standardized questions about strength of fertility motivation. Sociological Methodology 22: 37- 82.

Schoen, R., N.M. Astone, Y.J. Kim, C.A. Nathanson and J.M. Fields 1999. Do fertility intentions affect fertility behavior?. Journal of Marriage and the Family 61(3): 790-799.

Schwartz, A., N. Peacock, K. McRae, R. Seymour and M. Gilliam 2010. Defining new categories of pregnancy intention in African-American women. Womens Health Issues 20(6): 371-379.

Schwarz, E.B., P.A. Lohr, M.A. Gold and B. Gerbert 2007. Prevalence and correlates of ambivalence towards pregnancy among nonpregnant women. Contraception 75(4): 305-310.

Smallwood, S. and J. Jefferies 2003. Family building intentions in England and Wales: trends, outcomes and interpretations. Population Trends 112: 15-28.

Sobotka, T. 2009. Sub-replacement fertility intentions in Austria. European Journal of Population 25(4): 387-412. 
Sobotka, T. and M.R. Testa 2008. Attitudes and intentions toward childlessness in Europe. In People, Population Change and Policies, ed. C. Hohn, D. Avramov and I. Kotowska, 177-211. Springer.

Spéder, Z. and B. Kapitány 2009. How are time-dependent childbearing intentions realized? Realization, postponement, abandonment, bringing forward. European Journal of Population 25(4): 503-523.

Stanford, J.B., R. Hobbs, P. Jameson, M.J. DeWitt and R.C. Fischer 2000. Defining dimensions of pregnancy intendedness. Maternal and Child Health Journal 4(3): 183-189.

Stevens-Simon, C., J. Sheeder, R. Beach and S. Harter 2005. Adolescent pregnancy: do expectations affect intentions?. Journal of Adolescent Health 37: 243.e215-243.e222.

Testa, M.R. 2007. Childbearing preferences and family issues in Europe: evidence from the Eurobarometer 2006. Vienna Yearbook of Population Research Vol. 5: 357-379.

Testa, M.R. and L. Toulemon 2006. Family formation in France: individual preferences and subsequent outcomes. Vienna Yearbook of Population Research Vol.4: 41-75.

Thomson, E. 1997. Couple childbearing desires, intentions and births. Demography 34(3): 343-354.

Thomson, E. and Y. Brandreth 1995. Measuring fertility demand. Demography 32(1): 81-96.

Thomson, E. and J.M. Hoem 1998. Couple childbearing plans and births in Sweden. Demography 35(3): 315-322.

Toulemon, L. and M.R. Testa 2005. Fertility intentions and actual fertility: A complex relationship. Population and Societies 415.

Trussell, J., B. Vaughan and J. Stanford 1999. Are all contraceptive failures unintended pregnancies? Evidence from the 1995 National survey of family growth. Family Planning Perspectives 31(5): 246-247, 260.

Van Hoorn, W. and N. Keilman 1997. Birth expectations and their use in fertility forecasting. Eurostat, Eurostat Working Papers (Population and social condidtions) E4/1997-4.

Vignoli, D. and A. Régnier-Loilier 2010. Fertility dynamics in France and Italy. Who are the couples that do not give birth to the intended child? Università degli Studi di Firenze, Dipartimento di Statistica “G. Parenti” Working Paper 2010/07.

Westoff, C.F. 1981. The validity of birth intentions: evidence from U.S. longitudinal studies. In Predicting fertility. Demographic studies of birth expectations, ed. G.E. Hendershot and P.J. Placek, 51-59. Lexington, Mass.: Lexington Books.

Westoff, C.F., E.G. Mishler and E.L. Kelly 1957. Preferences in size of family and eventual fertility twenty years after. The American Journal of Sociology 62(5): 491-497.

Westoff, C.F., R.G. Potter, P.C. Sagi and E.G. Mishler 1961. Family growth in Metropolitan America. Princeton: Princeton University Press.

Westoff, C.F. and N.B. Ryder 1977. The predictive validity of reproductive intentions. Demography 14(4): 431-453.

Whelpton, P., A. Campbell and J. Paterson 1966. Fertility and family planning in the United States. Princeton University Press.

Woolf, M. and S. Pegden 1976. Families five years on. London: HMSO.

Zabin, L.S. 1999. Ambivalent feelings about parenthood may lead to inconsistent contraceptive use - and pregnancy. Family Planning Perspectives 31(5): 250-251. 
Zabin, L.S., G.R. Huggins, M.R. Emerson and V.E. Cullins. 2000. Partner effects on a woman's intention to conceive: "not with this partner". Family Planning Perspectives 32(1): 39-45.

\section{Appendix}

Table A1:

Coefficients of multinomial logistic regression of fertility intentions (reference response is "yes"). Childless women < 42. GB, GHS 1991-2005/7

\begin{tabular}{|c|c|c|c|c|c|c|c|c|c|c|}
\hline & & \multicolumn{3}{|c|}{ Probably yes } & \multicolumn{3}{|c|}{ Probably not } & \multicolumn{3}{|c|}{ No } \\
\hline & & Coeff & ient & $\begin{array}{l}\text { Std } \\
\text { err }\end{array}$ & Coeff & ient & $\begin{array}{l}\text { Std } \\
\text { err }\end{array}$ & Coeffi & ient & $\begin{array}{l}\text { Std } \\
\text { err }\end{array}$ \\
\hline \multirow{6}{*}{$\begin{array}{l}\text { Constant } \\
\text { Period }\end{array}$} & & -1.23 & $* * *$ & 0.09 & -2.72 & $* * *$ & 0.15 & -2.86 & $* * *$ & 0.16 \\
\hline & $1991-93$ & 0.13 & $*$ & 0.05 & 0.06 & & 0.08 & 0.06 & & 0.08 \\
\hline & $1994-96$ & 0.22 & $* * *$ & 0.05 & 0.24 & $* *$ & 0.08 & 0.06 & & 0.08 \\
\hline & 1998; 2000-01 & ref. & & & ref. & & & ref. & & \\
\hline & 2002-04 & -0.03 & & 0.05 & -0.04 & & 0.08 & -0.06 & & 0.08 \\
\hline & $2005-07$ & -0.01 & & 0.06 & -0.14 & & 0.10 & -0.16 & & 0.10 \\
\hline \multirow[t]{23}{*}{ Age } & 18 & 0.03 & & 0.09 & -0.84 & $* * *$ & 0.16 & -0.58 & $* * *$ & 0.18 \\
\hline & 19 & -0.23 & $*$ & 0.09 & -0.95 & $* * *$ & 0.16 & -0.69 & $* * *$ & 0.18 \\
\hline & 20 & -0.19 & $*$ & 0.09 & -0.90 & $* * *$ & 0.17 & -0.68 & $* * *$ & 0.19 \\
\hline & 21 & -0.09 & & 0.09 & -0.93 & $* * *$ & 0.17 & -0.75 & $* * *$ & 0.19 \\
\hline & 22 & 0.00 & & 0.09 & -0.70 & $* * *$ & 0.17 & -0.80 & $* * *$ & 0.20 \\
\hline & 24 & 0.07 & & 0.10 & -0.33 & $*$ & 0.17 & 0.08 & & 0.18 \\
\hline & 23 & -0.12 & & 0.09 & -0.56 & $* * *$ & 0.16 & -0.48 & * & 0.19 \\
\hline & 25 & ref. & & & ref. & & & ref. & & \\
\hline & 26 & 0.22 & $*$ & 0.10 & 0.08 & & 0.16 & 0.28 & & 0.18 \\
\hline & 27 & -0.02 & & 0.10 & -0.05 & & 0.17 & 0.10 & & 0.18 \\
\hline & 28 & 0.32 & $* *$ & 0.10 & 0.39 & $*$ & 0.16 & 0.60 & $* * *$ & 0.18 \\
\hline & 29 & 0.42 & $* * *$ & 0.11 & 0.86 & $* * *$ & 0.16 & 1.04 & $* * *$ & 0.17 \\
\hline & 30 & 0.66 & $* * *$ & 0.11 & 0.93 & $* * *$ & 0.16 & 1.24 & $* * *$ & 0.17 \\
\hline & 31 & 0.71 & $* * *$ & 0.12 & 1.00 & $* * *$ & 0.17 & 1.57 & $* * *$ & 0.17 \\
\hline & 32 & 0.83 & $* * *$ & 0.12 & 1.28 & $* * *$ & 0.16 & 1.74 & $* * *$ & 0.17 \\
\hline & 33 & 1.07 & $* * *$ & 0.13 & 1.70 & $* * *$ & 0.18 & 2.21 & $* * *$ & 0.18 \\
\hline & 35 & 1.20 & $* * *$ & 0.18 & 2.52 & $* * *$ & 0.20 & 3.04 & $* * *$ & 0.21 \\
\hline & 36 & 1.70 & $* * *$ & 0.19 & 2.87 & $* * *$ & 0.22 & 3.50 & $* * *$ & 0.22 \\
\hline & 37 & 1.65 & $* * *$ & 0.24 & 3.36 & $* * *$ & 0.24 & 4.02 & $* * *$ & 0.25 \\
\hline & 38 & 1.72 & $* * *$ & 0.27 & 3.84 & $* * *$ & 0.27 & 4.39 & $* * *$ & 0.27 \\
\hline & 39 & 1.69 & $* * *$ & 0.29 & 3.63 & $* * *$ & 0.29 & 4.67 & $* * *$ & 0.28 \\
\hline & 40 & 2.21 & $* * *$ & 0.44 & 4.59 & $* * *$ & 0.42 & 5.65 & $* * *$ & 0.42 \\
\hline & 41 & 2.09 & $* * *$ & 0.59 & 4.78 & $* * *$ & 0.55 & 6.26 & $* * *$ & 0.54 \\
\hline \multirow{3}{*}{$\begin{array}{l}\text { Living } \\
\text { with... }\end{array}$} & Spouse & ref. & & & ref. & & & ref. & & \\
\hline & Partner & 0.32 & $* *$ & 0.11 & 0.40 & $* *$ & 0.14 & 0.44 & $* * *$ & 0.13 \\
\hline & Alone & 0.89 & $* * *$ & 0.11 & 1.18 & $* * *$ & 0.13 & 0.91 & $* * *$ & 0.13 \\
\hline
\end{tabular}


Table A1 (continued)

\begin{tabular}{|c|c|c|c|c|c|c|c|c|c|}
\hline \multirow{3}{*}{$\begin{array}{l} \\
\begin{array}{l}\text { Quali- } \\
\text { fications }\end{array}\end{array}$} & \multirow{3}{*}{ Degree } & \multicolumn{2}{|c|}{ Probably yes } & \multicolumn{3}{|c|}{ Probably not } & \multicolumn{3}{|c|}{ No } \\
\hline & & Coefficient & \multirow{2}{*}{$\begin{array}{c}\begin{array}{l}\text { Std } \\
\text { err }\end{array} \\
0.05\end{array}$} & \multicolumn{2}{|c|}{ Coefficient } & $\begin{array}{l}\text { Std } \\
\text { err }\end{array}$ & \multicolumn{2}{|c|}{ Coefficient } & \multirow{2}{*}{$\begin{array}{c}\begin{array}{c}\text { Std } \\
\text { err }\end{array} \\
0.09\end{array}$} \\
\hline & & 0.08 & & -0.08 & & 0.08 & -0.47 & $* * *$ & \\
\hline & $\begin{array}{l}\text { Other } \\
\text { post-A } \\
\text { A level }\end{array}$ & $\begin{array}{l}0.04 \\
\text { ref. }\end{array}$ & 0.07 & $\begin{array}{l}0.01 \\
\text { ref. }\end{array}$ & & 0.10 & 0.01 & & 0.10 \\
\hline & $\mathrm{O} / \mathrm{CSE} / \mathrm{cler}$. & -0.01 & 0.05 & 0.11 & & 0.07 & 0.25 & $* * *$ & 0.07 \\
\hline & Other & -0.13 & 0.13 & 0.10 & & 0.20 & 0.30 & & 0.19 \\
\hline & None & 0.18 & 0.09 & 0.49 & $* * *$ & 0.12 & 1.32 & $* * *$ & 0.11 \\
\hline \multirow{3}{*}{$\begin{array}{l}\text { No. of } \\
\text { marriages }\end{array}$} & 0 & -0.02 & 0.11 & 0.04 & & 0.13 & -0.09 & & 0.12 \\
\hline & 1 & ref. & & ref. & & & ref. & & \\
\hline & $2+$ & -0.16 & 0.19 & -0.17 & & 0.23 & 0.39 & $*$ & 0.19 \\
\hline \multirow[t]{5}{*}{ SEG } & Employers & 0.00 & 0.04 & 0.03 & & 0.07 & 0.04 & & 0.07 \\
\hline & Intermediate & ref. & & ref. & & & ref. & & \\
\hline & Ps \& skilled & -0.01 & 0.05 & 0.17 & $*$ & 0.07 & 0.37 & $* * *$ & 0.07 \\
\hline & Unskilled & 0.10 & 0.10 & 0.33 & $*$ & 0.15 & 0.52 & $* * *$ & 0.14 \\
\hline & Other & -0.09 & 0.07 & 0.04 & & 0.12 & 0.16 & & 0.13 \\
\hline Country & $U K$ & ref. & & ref. & & & ref. & & \\
\hline of birth & Other & -0.16 & 0.06 & -0.47 & $* * *$ & 0.09 & -0.66 & $* * *$ & 0.10 \\
\hline
\end{tabular}

Note: $* \mathrm{p}<0.05, * * \mathrm{p}<.0 .01, * * * \mathrm{p}<0.001$

Table A2:

Coefficients of multinomial logistic regression of fertility intentions (reference response is "yes"). Women of parity $1+$ women aged < 42. GB, GHS 1991-2005/7

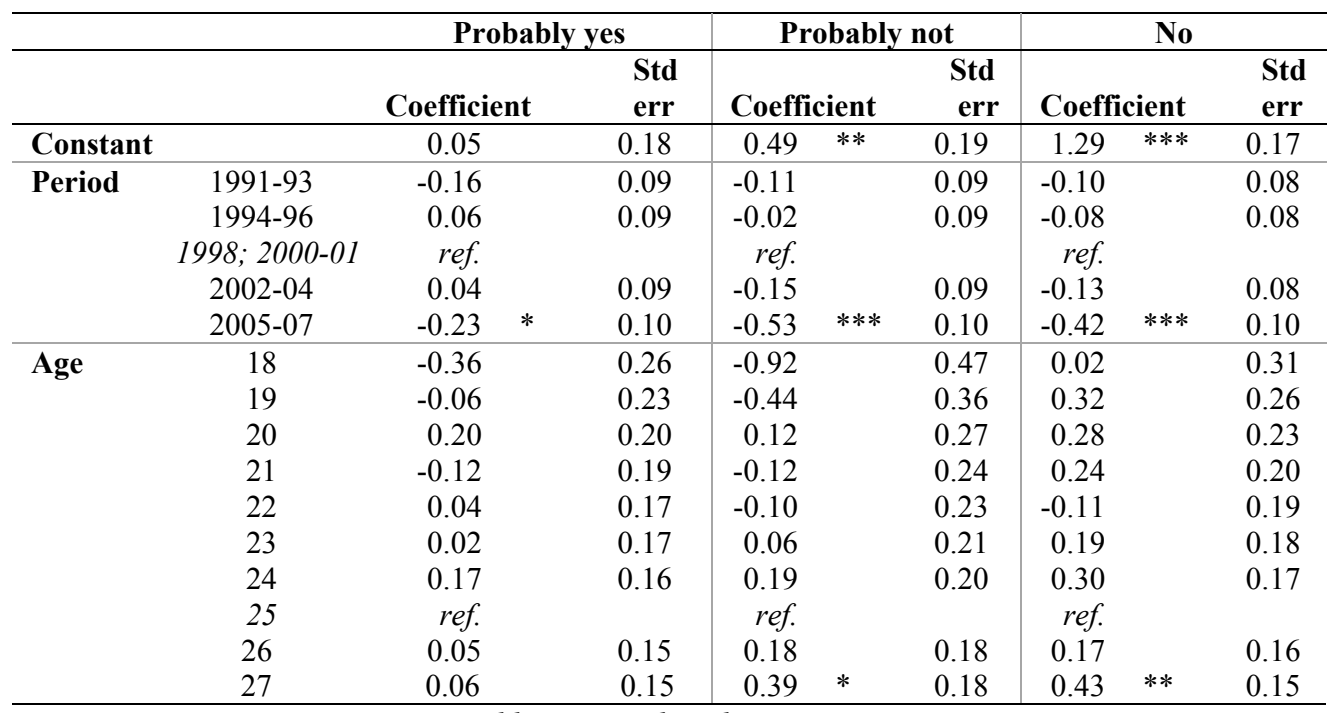


Table A2 (continued)

\begin{tabular}{|c|c|c|c|c|c|c|c|c|c|c|}
\hline & & \multicolumn{3}{|c|}{ Probably yes } & \multicolumn{3}{|c|}{ Probably not } & \multicolumn{3}{|c|}{ No } \\
\hline & & Coeff & cient & $\begin{array}{l}\text { Std } \\
\text { err }\end{array}$ & Coeff & ient & $\begin{array}{l}\text { Std } \\
\text { err }\end{array}$ & Coef & cient & $\begin{array}{l}\text { Std } \\
\text { err }\end{array}$ \\
\hline \multirow[t]{14}{*}{ Age } & 28 & 0.30 & $*$ & 0.15 & 0.48 & $* *$ & 0.17 & 0.51 & $* * *$ & 0.15 \\
\hline & 29 & 0.33 & $*$ & 0.15 & 0.65 & $* * *$ & 0.17 & 0.71 & $* * *$ & 0.15 \\
\hline & 30 & 0.42 & $* *$ & 0.15 & 0.83 & $* * *$ & 0.17 & 0.84 & $* * *$ & 0.15 \\
\hline & 31 & 0.52 & $* * *$ & 0.15 & 1.03 & $* * *$ & 0.17 & 1.16 & $* * *$ & 0.15 \\
\hline & 32 & 0.66 & $* * *$ & 0.16 & 1.35 & $* * *$ & 0.17 & 1.32 & $* * *$ & 0.15 \\
\hline & 33 & 0.67 & $* * *$ & 0.16 & 1.33 & $* * *$ & 0.18 & 1.53 & $* * *$ & 0.16 \\
\hline & 34 & 0.56 & $* *$ & 0.17 & 1.52 & $* * *$ & 0.18 & 1.66 & $* * *$ & 0.16 \\
\hline & 35 & 0.68 & $* * *$ & 0.19 & 1.56 & $* * *$ & 0.20 & 1.83 & $* * *$ & 0.18 \\
\hline & 36 & 0.48 & $*$ & 0.22 & 1.93 & $* * *$ & 0.21 & 2.32 & $* * *$ & 0.19 \\
\hline & 37 & 0.62 & $* *$ & 0.23 & 2.06 & $* * *$ & 0.22 & 2.52 & $* * *$ & 0.20 \\
\hline & 38 & 0.51 & $*$ & 0.26 & 2.27 & $* * *$ & 0.24 & 2.70 & $* * *$ & 0.22 \\
\hline & 39 & 0.60 & $*$ & 0.30 & 2.36 & $* * *$ & 0.27 & 3.05 & $* * *$ & 0.25 \\
\hline & 40 & 0.77 & $*$ & 0.30 & 2.23 & $* * *$ & 0.29 & 3.07 & $* * *$ & 0.27 \\
\hline & 41 & 0.69 & & 0.43 & 2.98 & $* * *$ & 0.37 & 3.87 & $* * *$ & 0.36 \\
\hline \multirow{11}{*}{$\begin{array}{l}\text { Open } \\
\text { interval }\end{array}$} & 0 & -0.26 & $*$ & 0.10 & -0.72 & $* * *$ & 0.11 & -0.96 & $* * *$ & 0.10 \\
\hline & 1 & -0.22 & $*$ & 0.10 & -0.55 & $* * *$ & 0.11 & -0.70 & $* * *$ & 0.10 \\
\hline & 2 & -0.03 & & 0.11 & -0.18 & & 0.11 & -0.21 & $*$ & 0.10 \\
\hline & 3 & ref. & & & ref. & & & ref. & & \\
\hline & 4 & 0.19 & & 0.13 & 0.21 & & 0.13 & 0.41 & $* * *$ & 0.12 \\
\hline & 5 & 0.36 & $*$ & 0.15 & 0.37 & $*$ & 0.15 & 0.60 & $* * *$ & 0.14 \\
\hline & 6 & 0.45 & $* *$ & 0.17 & 0.57 & $* * *$ & 0.17 & 0.86 & $* * *$ & 0.15 \\
\hline & 7 & 0.37 & $*$ & 0.19 & 0.51 & $* *$ & 0.18 & 0.82 & $* * *$ & 0.17 \\
\hline & 8 & 0.47 & $*$ & 0.21 & 0.61 & $* *$ & 0.20 & 1.08 & $* * *$ & 0.18 \\
\hline & 9 & 0.38 & & 0.24 & 0.55 & $*$ & 0.23 & 1.11 & $* * *$ & 0.21 \\
\hline & $10+$ & 0.42 & $*$ & 0.17 & 0.71 & $* * *$ & 0.16 & 1.60 & $* * *$ & 0.14 \\
\hline \multirow[t]{3}{*}{ Parity } & 1 & -0.82 & $* * *$ & 0.07 & -1.69 & $* * *$ & 0.07 & -2.38 & $* * *$ & 0.06 \\
\hline & 2 & ref. & & & ref. & & & ref. & & \\
\hline & $3+$ & 0.31 & $* *$ & 0.12 & 0.46 & $* * *$ & 0.11 & 0.88 & $* * *$ & 0.11 \\
\hline \multirow{3}{*}{$\begin{array}{l}\text { Living } \\
\text { with... }\end{array}$} & Spouse & ref. & & & ref. & & & ref. & & \\
\hline & Partner & -0.06 & & 0.12 & -0.35 & $* *$ & 0.12 & -0.45 & $* * *$ & 0.11 \\
\hline & Alone & 0.68 & $* * *$ & 0.11 & 0.69 & $* * *$ & 0.10 & 0.33 & $* * *$ & 0.10 \\
\hline \multirow{6}{*}{$\begin{array}{l}\text { Quali- } \\
\text { fications }\end{array}$} & Degree & -0.05 & & 0.11 & -0.19 & & 0.11 & -0.63 & $* * *$ & 0.10 \\
\hline & Other post-A & 0.08 & & 0.12 & 0.02 & & 0.12 & 0.01 & & 0.11 \\
\hline & A level & ref. & & & ref. & & & ref. & & \\
\hline & $\mathrm{O} / \mathrm{CSE} / \mathrm{cler}$ & 0.03 & & 0.08 & -0.09 & & 0.08 & 0.15 & & 0.08 \\
\hline & Other & -0.21 & & 0.18 & -0.28 & & 0.19 & 0.00 & & 0.17 \\
\hline & None & 0.00 & & 0.10 & -0.30 & $* *$ & 0.11 & 0.22 & $*$ & 0.10 \\
\hline \multirow{3}{*}{$\begin{array}{l}\text { No. of } \\
\text { marriages }\end{array}$} & 0 & 0.22 & $*$ & 0.11 & 0.27 & $*$ & 0.11 & 0.25 & $*$ & 0.10 \\
\hline & 1 & ref. & & & ref. & & & ref. & & \\
\hline & $2+$ & -0.22 & & 0.13 & -0.44 & $* * *$ & 0.12 & -0.42 & $* * *$ & 0.11 \\
\hline \multirow[t]{5}{*}{ SEG } & Employers & -0.01 & & 0.08 & 0.01 & & 0.08 & -0.05 & & 0.07 \\
\hline & Intermediate & ref. & & & ref. & & & ref. & & \\
\hline & Ps \& skilled & 0.11 & & 0.07 & -0.02 & & 0.07 & 0.22 & $* * *$ & 0.06 \\
\hline & Unskilled & 0.04 & & 0.12 & -0.19 & & 0.13 & 0.12 & & 0.11 \\
\hline & Other & -0.06 & & 0.14 & -0.46 & $* *$ & 0.15 & -0.28 & $*$ & 0.13 \\
\hline Country & $U K$ & ref. & & & ref. & & & ref. & & \\
\hline of birth & Other & 0.18 & $*$ & 0.08 & -0.41 & $* * *$ & 0.09 & -0.62 & $* * *$ & 0.08 \\
\hline
\end{tabular}

Note: ${ }^{*} p<0.05, * * p<.0 .01, * * * p<0.001$ 
